\title{
Von Willebrand factor with increased binding capacity is associated with reduced platelet aggregation but enhanced agglutination in COVID-19 patients: another COVID-19 paradox?
}

\author{
Franco Ruberto ${ }^{1}$ - Antonio Chistolini ${ }^{2}$ - Mariaignazia Curreli ${ }^{3}$. Giacomo Frati ${ }^{4,5}$ - Antonino G. M. Marullo ${ }^{4}$ \\ Giuseppe Biondi-Zoccai $^{4,6} \cdot$ Massimo Mancone $^{7} \cdot$ Sebastiano Sciarretta $^{4,5} \cdot$ Fabio Miraldi $^{7} \cdot$ Francesco Alessandri $^{1}$. \\ Giancarlo Ceccarelli $^{8}$. Francesco Barone ${ }^{2}$. Cristina Santoro ${ }^{2}$. Domenico Alvaro ${ }^{9}$. Francesco Pugliese ${ }^{1}$. \\ Fabio M. Pulcinelli ${ }^{3}$ on behalf of Policlinico Umberto I COVID-19 Group
}

Accepted: 9 November 2020 / Published online: 2 January 2021

(c) Springer Science+Business Media, LLC, part of Springer Nature 2021

\begin{abstract}
Patients with Coronavirus-associated disease-2019 (COVID-19) display alterations of the hemostatic system and the presence of a prothrombotic status frequently leading to vascular complications. However, the impact of COVID-19 on platelet activity, aggregation and agglutination still needs to be clarified. We measured total levels of von Willebrand factor (vWF) and vWF binding to the platelet glycoprotein (Gp) complex (GPIb-IX-V), in a cohort of COVID-19 patients admitted to the intensive care unit of our Institution. Moreover, we evaluated platelet aggregation in response to agonists (ADP, collagen, arachidonic acid) and platelet agglutination in response to ristocetin. We found that levels of vWF antigen and the active form of vWF binding to platelets ( $\mathrm{WWF}: \mathrm{RCo}$ ), were markedly increased in these patients. These results were associated with higher agglutination rates induced by ristocetin, thereby indirectly indicating an increased capability of vWF to bind to platelets. Conversely, we found that platelet aggregation in response to both ADP and collagen was lower in COVID19 patients compared to healthy volunteers. This study shows that COVID-19 is associated with increased vWF-induced platelet agglutination but reduced platelet responsivity to aggregation stimuli. Our findings have translational relevance since platelet adhesion to vWF may represent a marker to predict possible complications and better delineate therapeutic strategies in COVID-19 patients.
\end{abstract}

Keywords Covid $19 \cdot$ Platelets · vonWillebrand factor

\section{Highlights}

Franco Ruberto and Antonio Chistolini contributed equally to this work.

The members of Policlinico Umberto I COVID-19 Group has been listed in Acknowledgement.

Electronic Supplementary Material The online version of this article (https://doi.org/10.1007/s11239-020-02339-6) contains supplementary material, which is available to authorized users.

Fabio M. Pulcinelli

fabio.pulcinelli@uniroma1.it

Extended author information available on the last page of the article
- Patients with Coronavirus-associated disease-2019 (COVID-19) display alterations of the hemostatic system and the presence of a prothrombotic status frequently leading to vascular complications.

- Levels of vWF antigen and the active form of vWF binding to platelets (vWF:RCo), are markedly increased in these patients.

- Platelet aggregation in response to both ADP and collagen was lower in COVID-19 patients compared to healthy volunteers.

- Higher ristocetin induced agglutination in patients with COVID-19 indicates an increased capability of VWF to form platelet emboli. 


\section{Introduction}

Since the sudden outbreak of novel SARS coronavirus, which was firstly reported in Wuhan, China, in December 2019, the rapid spread of this new viral infection has become a big concern worldwide. On October 6th, 2020, more than 35 million COVID-19 cases have been diagnosed in 212 different countries (Johns Hopkins University-Coronavirus Resource Center last accessed on October 6th, 2020), with more than 1,000,000 deaths associated with severe acute respiratory syndrome-coronavirus-2 (SARS-CoV-2) infection [1]. COVID-19 is characterized by bilateral interstitial pneumonia, with important impairment of oxygenation and a mortality rate ranging from 1 to $15 \%$. More recently, the pathophysiological and clinical characteristics of hospitalized patients, as well as laboratory findings and autopsy data have suggested that patterns of the disease, with infected patients experiencing not only interstitial pneumonia, also present vasculitis, acute cardiovascular events, thrombosis and thromboembolism [2]. In particular, it was recently demonstrated that pulmonary embolism is a frequent cause of death in COVID-19 patients [3]. The presence of a prothrombotic status in subjects with COVID-19 appears to be dependent on vascular inflammation, endothelial damage and on derangements of the coagulation and hemostasis systems. Although previous studies reported thrombocytopenia in patients with SARS-CoV2 infection [4], the impact of COVID-19 on platelet activity, aggregation and agglutination is still to be clarified. This would help to develop new therapeutic strategies for patients suffering from such disease.

Therefore, in this paper we measured total levels of VWF-Antigen (VWF:Ag) and its capability to adhere to platelet glycoprotein complex, GPIb-IX-V (VWF-Ristocetin Cofactor, VWF:RCo), in a cohort of patients with severe COVID-19 under heparin treatment. Moreover, we evaluated platelet aggregation in response to ADP, Collagen, Arachidonic Acid and platelet agglutination in response to ristocetin in these subjects.

\section{Matherials and methods}

The study was approved by the Ethics Committee of "Sapienza" University of Rome (No109/2020). From April to May 2020 a consecutive series of 32 critical COVID-19 patients suffering from a bilateral interstitial pneumonia and admitted to the ICU of a teaching tertiary hospital were enrolled in the study. Inclusion criteria and exclusion criteria were reported in supplemental data. Nine patients were excluded due to these exclusion criteria (two for previous history of coagulopathy, three for antiplatelet therapy, four for thrombocytopenia). Four patients were excluded because of chylous blood sample not suitable for further investigation. Ten healthy volunteers (HV), that gave written informed consent, were enrolled as control group, they were chosen among students of the postgraduate schools and health personnel of our hospital. Demographic characteristics of patients and of healthy volunteers (HV) are reported in Table 1.

Since it was found a viral presence in plasma of infected patients [5], all procedures were carried out following the Laboratory biosafety guidance related to COVID-19 of the World Health Organization Interim guidance 19 March 2020 .

Table 1 Characteristics of COVID-19 patients and healthy volunteers (HV)

\begin{tabular}{|c|c|c|c|}
\hline Characteristic & Covid-19 n = 19 & $\mathrm{HV} n=10$ & $\mathrm{p}$ value* \\
\hline \multicolumn{4}{|l|}{$\begin{array}{l}\text { Demographic charac- } \\
\text { teristics }\end{array}$} \\
\hline Age-yr & $69 \pm 12.8$ & $35 \pm 9$ & $\mathrm{p}<0.00001$ \\
\hline Gender (F/M) & $9 / 10$ & $4 / 6$ & NS \\
\hline SAPS II & $34 \pm 8.6$ & 0 & $\mathrm{p}<0.00001$ \\
\hline \multicolumn{4}{|l|}{ Medical hystory } \\
\hline Hypertension & $78.9 \%$ & $10.0 \%$ & $\mathrm{p}<0.0004$ \\
\hline Diabetes & $21 \%$ & $0 \%$ & NS \\
\hline Smoke & $26.3 \%$ & $40.0 \%$ & NS \\
\hline Obesity & $10.5 \%$ & $10.0 \%$ & NS \\
\hline \multicolumn{4}{|l|}{$\begin{array}{l}\text { Symptons at disease } \\
\text { onset }\end{array}$} \\
\hline Fever & $100 \%$ & $0 \%$ & $\mathrm{p}<0.00001$ \\
\hline Dyspnea & $57.8 \%$ & $0 \%$ & $\mathrm{p}<0.00001$ \\
\hline Cough & $89.5 \%$ & $0 \%$ & $\mathrm{p}<0.0023$ \\
\hline Diarrhea & $15.7 \%$ & $0 \%$ & NS \\
\hline Other & $5.2 \%$ & $0 \%$ & NS \\
\hline \multicolumn{4}{|l|}{ Laboratory findings } \\
\hline $\begin{array}{l}\text { Red-cell count }(\times \\
\left.10^{12} / \mathrm{L}\right)\end{array}$ & $4 \pm 1$ & $5 \pm 0.3$ & $\mathrm{p}<0.002$ \\
\hline $\begin{array}{l}\text { White-cell count }(\times \\
\left.10^{9} / \mathrm{L}\right)\end{array}$ & $8.8 \pm 5.4$ & $7.1 \pm 0.9$ & $\mathrm{p}<0.00001$ \\
\hline \multicolumn{4}{|l|}{$\begin{array}{l}\text { Differential count }(\times \\
\left.10^{9} / \mathrm{L}\right)\end{array}$} \\
\hline Total neutrophils & $7.4 \pm 5.1$ & $4.2 \pm 0.6$ & $\mathrm{p}<0.00001$ \\
\hline Total lymphocytes & $0.9 \pm 0.7$ & $2.4 \pm 0.3$ & $\mathrm{p}<0.00001$ \\
\hline Total monocytes & $0.4 \pm 0.2$ & $0.6 \pm 0.2$ & $\mathrm{p}<0.00001$ \\
\hline Platelet count $\left(\times 10^{9} / \mathrm{L}\right)$ & $218 \pm 95$ & $249 \pm 49$ & NS \\
\hline Hemoglobin (g/liter) & $11 \pm 2$ & $14 \pm 1$ & $\mathrm{p}<0.01$ \\
\hline Hematocrit (\%) & $34 \pm 5$ & $41 \pm 1$ & $\mathrm{p}<0.00001$ \\
\hline MPV (fl) & $10 \pm 2$ & $9.2 \pm 0.7$ & $\mathrm{p}<0.001$ \\
\hline PDW & $16 \pm 7$ & $12.7 \pm 1.5$ & $\mathrm{p}<0.002$ \\
\hline
\end{tabular}

*p values refer to Mann-Whitney $U$ test for the quantitative variables and to Fisher's exact probability test for the categorical variables. 
Accordingly, for safety reasons, we studied platelet aggregation with the 96-well plate aggregation method [6].

All methodological procedures have been carried out in accordance $[7,8]$ and reported in detail in supplemental data.

\section{Results}

We observed increased circulating levels of VWF:Ag in COVID-19 patients, $(331.4 \pm 104.5$ IU/dl in COVID19 patients vs. normal reference values of 50-160 IU/dl). In addition, we found a marked increase in the levels of VWF:RCo $(321.7 \pm 149.4 I U / d l$ in COVID-19 patients vs. normal reference values of 41-101 IU/dl and 50-130 IU/ $\mathrm{dl}$ in blood group $\mathrm{O}$ and non $\mathrm{O}$, respectively). All patients had both VWF:Ag and VWF:RCo levels higher than normal values.

In order to verify platelet functionality in COVID-19 patients, we performed platelet aggregation studies. The results showed that both ADP- and collagen-induced platelet aggregation were significantly reduced in COVID-19 patients, as compared to HV. In fact, the maximum aggregation percentages induced by ADP $(4 \mu \mathrm{M}$ or $10 \mu \mathrm{M})$ and collagen $(2 \mu \mathrm{g} / \mathrm{ml}$ or $5 \mu \mathrm{g} / \mathrm{ml})$ were significantly reduced as compared to HV (Fig. 1a-b). On the other hand, we did not observe significant differences in platelet aggregation between the 2 groups in response to arachidonic acid $(0.5$ $\mathrm{mM})$ or ADP $(4 \mu \mathrm{M})$ plus arachidonic acid $(0.5 \mathrm{mM})$, used as maximal aggregation stimulus (Fig. 1c).

Since ristocetin promotes the interaction between VWF and its platelet receptor, we studied platelet agglutination induced by ristocetin in the last 12 consecutive patients with SARS-CoV2 infection and in the last 7 consecutive HVs once the observation of elevated levels of vWF antigen was made. In 3 patients we were unable to carry out the study due to insufficient platelet levels in the Platelet Rich Plasma (PRP). The results showed an increase in the rates of agglutination induced by ristocetin $(1.5 \mathrm{mg} / \mathrm{ml})$ in patients COVID-19 patients, as compared to HV (mean $55.4 \% \pm 10.5 \%$ vs $38.0 \% \pm 5.3 \%$; median $53 \%$ vs $39 \%$; $\mathrm{p}=0.004)$. Lower ristocetin concentration was necessary to induce platelet agglutination that exceeds both $20 \%$ and $40 \%$ in COVID-19 patients (Fig. 1d) compared to HV. These results indicate a higher ability of VWF to bind to platelets. Notably all Covid-19 patients had ristocetin concentration which reached $40 \%$ of agglutination lower than all those found in all healthy volunteers.

\section{Discussion}

In this study we demonstrate that both VWF:Ag and VWF:RCo, are markedly increased in patients with severe COVID-19 infection as compared to normal reference values. In particular, VWF:RCo values were on average 3 times higher than the maximum normal reference values. These results were associated with higher agglutination rates induced by ristocetin in patients with COVID-19, thereby indirectly indicating an increased capability of VWF to bind to platelets.

Surprisingly, we found that platelet aggregation in response to both ADP and collagen was lower in patients with severe COVID-19 infection compared to HV. These results are similar to data observed in patients with dengue virus infection, which is associated with higher circulating VWF levels and increased platelet agglutination induced by ristocetin, even at low concentrations [9]. Of note, also in patients suffering from dengue fever platelets are hyporeactive [9]. The reduced ability of platelets to get activated after stimulation may depend on several factors. Platelets exhaustion/clearance is a possible mechanism since it is likely that platelets are hyper-activated in the initial stage of COVID-19 disease and then become hyporeactive in the later stages. Noteworthy, also in some cases of dengue fever infection a prothrombotic status was described in the initial stage of the infection [10]. Another mechanism leading to reduced platelet aggregation may rely on higher concentrations of VWF, which may bind to platelet receptor for fibrinogen thus reducing aggregation. Finally, we can exclude that a lower platelet concentration affects aggregation in samples from patients suffering from COVID-19, as the response to all the agonists tested did not show any difference between the two subgroups divided by the platelet number in PRP (Supplemental data).

Since it was previously shown that high levels of VWF and the subsequent formation of platelet aggregates may occlude arterioles and capillaries [11], we can speculate that-virus-induced endothelial inflammation, in addition to clot formation, might be able to increase VWF:Ag and consequently VWF:RCo, thereby triggering VWF binding to platelets and leading to occlusion of microcirculation vessels (Fig. 2).

Our paper may be of translational relevance since platelet adhesion to VWF may represent a predictive marker to assess the course of patients with COVID-19, predicting possible complications and better delineating therapeutic strategies. Recently it was found that treatment with dexamethasone reduces mortality in patients with Covid-19 who are receiving respiratory support [12], with our paper we can speculate that the beneficial effect of dexamethasone may depend on the capacity of the drug to modulate endothelial inflammation.

Our study has some limitations. For safety reasons, we could not perform standard assays to measure platelet aggregation. However, our new method proved to be effective in properly detecting platelet activation in response to agonists. Ristocetin assay was only begun after the study 
A

ADP

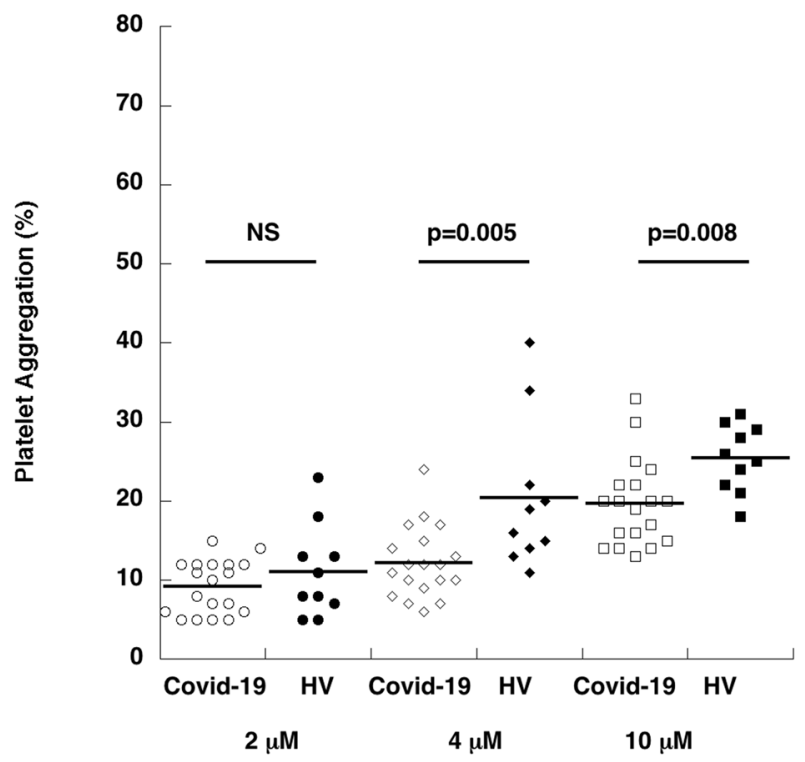

C Arachidonic Acid - ADP + Arachidonic Acid

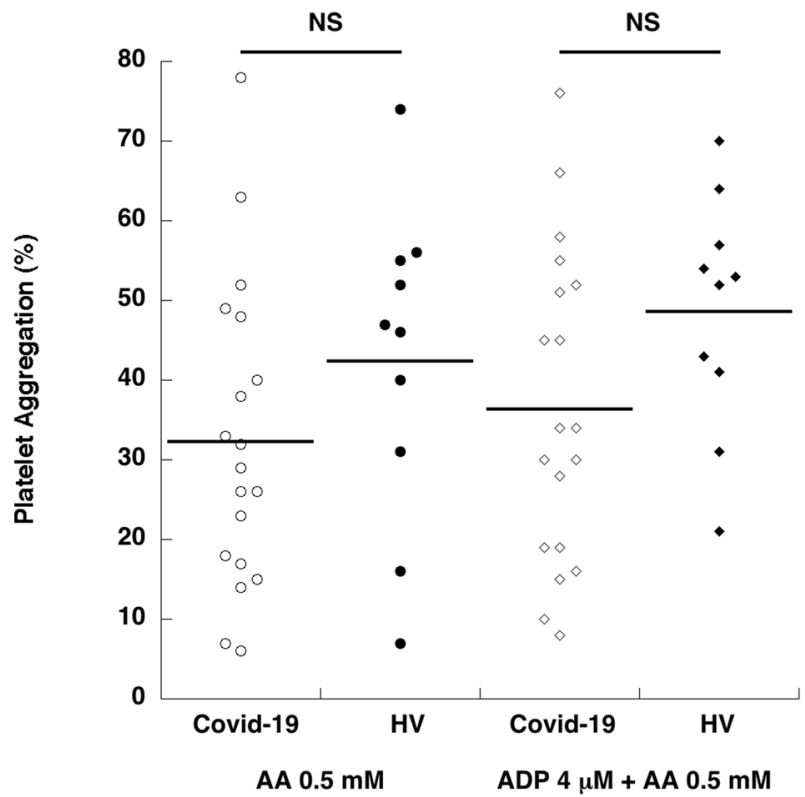

Fig. 1 Dot plot of platelet aggregation induced by ADP 2, 4 and 10 $\mu \mathrm{M}$ (Panel A), Collagen 2 and $5 \mu \mathrm{g} / \mathrm{ml}$ (Panel B) Arachidonic Acid $0.5 \mathrm{mM}$ and ADP $4 \mu \mathrm{M}$ plus Arachidonic Acid $0.5 \mathrm{mM}$ (Panel C) in COVID-19 acute infection patients $(\mathrm{N}=20)$ versus Healthy Volunteers $(\mathrm{HV}, \mathrm{N}=10)$. Platelet aggregation is reported as maximal percentage evaluated after $6 \mathrm{~min}$ (PA\%). Statistical data were evaluated by Wilcoxon-Mann-Whitney rank sum test for upaired data. Dot blot of ristocetin $(0.75-1.5 \mathrm{mg} / \mathrm{ml})$ induced platelet agglutination (Panel
B

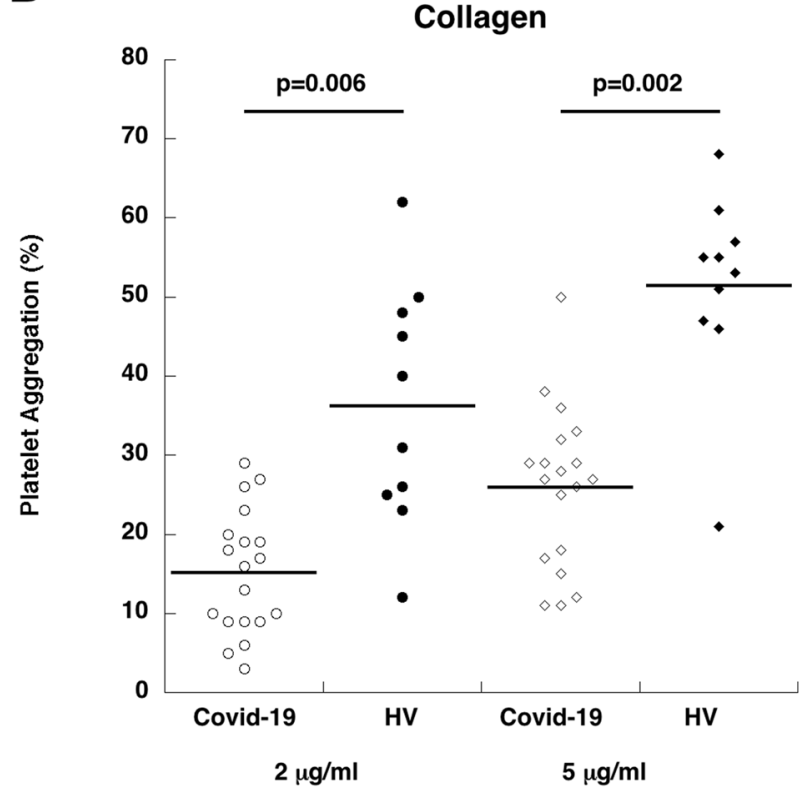

D

Ristocetin

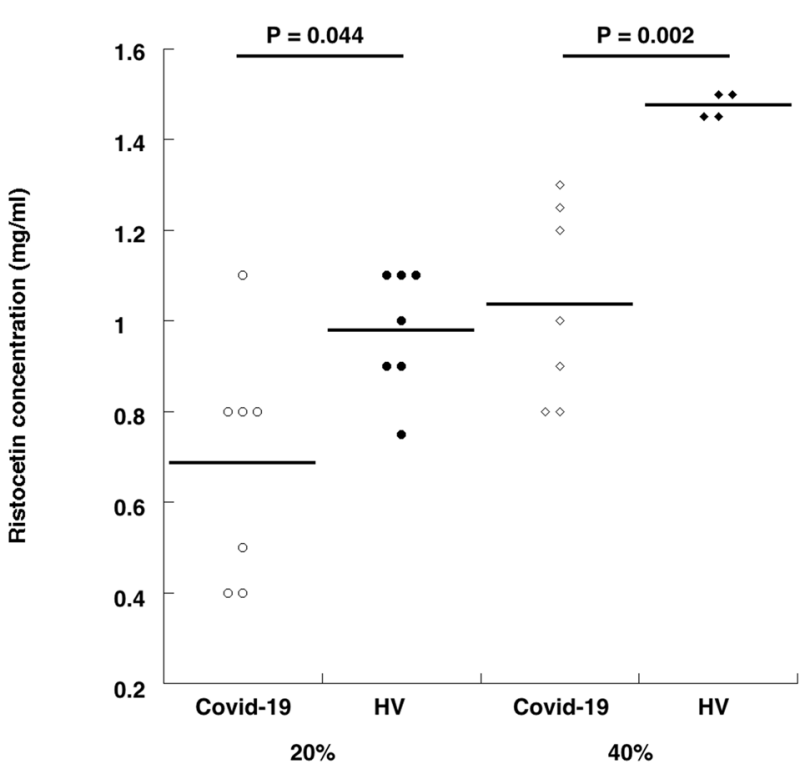

D) in COVID-19 acute infection patients $(\mathrm{N}=10)$ versus Healthy Volunteers $(\mathrm{HV}, \mathrm{N}=7)$. The results are reported as the ristocetin concentrations that exceed $20 \%$ and $40 \%$ of agglutination. $3 \mathrm{HV}$ had an agglutination induced by ristocetin lower by $40 \%$ (32\%, 38\% and 39\% respectively) at the highest concentration of ristocetin used $(1.5 \mathrm{mg} / \mathrm{ml})$ and have not been reported in this figure 1 panel $\mathrm{D}$, section $40 \%$. Statistical data were evaluated by Wilcoxon-Mann-Whitney rank sum test for unpaired data. 
Fig. 2 Higher platelets agglutination rates in COVID-19 patients with an increased capability of VWF to bind to platelets finally leading to thromboembolic events

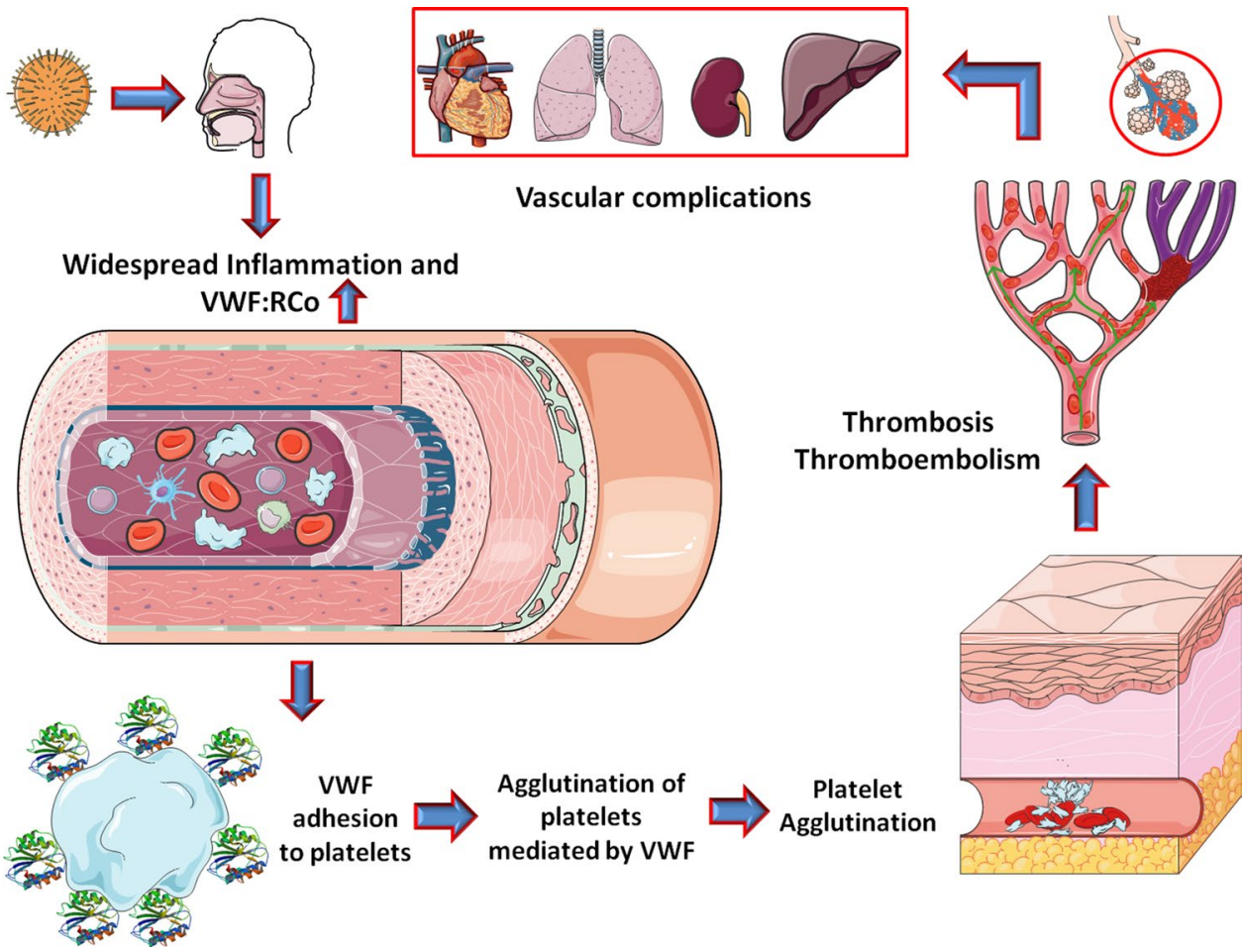

was started, thus not all patients in either cohort were studied. The effects of those missing patients are unknown. Finally, sample size was quite small. The real impact of platelet abnormalities on patients with COVID-19 warrants further clarification in larger studies.

Acknowledgements This study was supported by a Grant from "Sapienza" - University of Rome 2018 to F.M.P.

Policlinico Umberto I COVID-19 Group Alida Albante, Francesco Alessandri, Domenico Alvaro, Guido Antonelli, Fabio Araimo-Morselli, Daniela Auricchio, Francesco Barone, Federico Bilotta, Giuseppe Biondi-Zoccai Matteo Brisciani, Katia Bruno, Alessandro Cappannoli, Vincenzo Cardinale, Giancarlo Ceccarelli, Paola Celli, Antonio Chistolini, Stella Consolo, Claudia Croce, Beatrice Crocitti, Mariaignazia Curreli, Gabriella D'Ettorre, De Lauri Daniela, Francesco De Lazzaro, Francesco Fedele, Giacomo Frati, Gioacchino Galardo, Lorena Giannetti, Stefano Ianni, Carmela Imperiale, Viviana Maestrini, Eugenia Magnanimi, Federica Maldarelli, Massimo Mancone, Sabina Martelli, Antonino G.M. Marullo, Claudio Mastroianni, Teresa Messina, Fabio Miraldi, Elisa Pattelli, Filippo Pecorari, Serena Perrella, Mario Piazzolla, Monica Portieri, Francesco Pugliese, Fabio M. Pulcinelli, Fabiola Ratini, Claudia Ricci, Franco Ruberto, Pietro Santopietro, Guglielmo Tellan, Luca Titi, Paolo Tordiglione, Antonella Tosi, Fausto Trigilia, Cristina Santoro, Sebastiano Sciarretta.

\section{Compliance with ethical standards}

Conflict of interest All authors declare that there is no conflict of interest.

\section{References}

1. Sohrabi C, Alsafi Z, O’Neill N, Khan M, Kerwan A, Al-Jabir A, Iosifidis C, Agha R (2020) World health organization declares global emergency: a review of the 2019 novel coronavirus (COVID-19). Int J Surg 76:71-76. https://doi.org/10.1016/j. ijsu.2020.02.034

2. Biondi Zoccai G, Landoni G, Carnevale R, Cavarretta E, Sciarretta S, Frati G (2020) SARS-CoV-2 and COVID-19: facing the pandemic together as citizens and cardiovascular practitioners. Minerva Cardioangiol 68(2):61-64. https://doi.org/10.23736/ S0026-4725.20.05250-0

3. Lax SF, Skok K, Zechner P, Kessler HH, Kaufmann N, Koelblinger C, Vander K, Bargfrieder U, Trauner M (2020) Pulmonary arterial thrombosis in COVID-19 with fatal outcome: results from a prospective single-center, clinicopathologic case series. Ann Intern Med. https://doi.org/10.7326/M20-2566

4. Thachil J, Tang N, Gando S, Falanga A, Cattaneo M, Levi M, Clark C, Iba T (2020) ISTH interim guidance on recognition and management of coagulopathy in COVID-19. J Thromb Haemost 18(5):1023-1026. https://doi.org/10.1111/jth.14810

5. Lescure FX, Bouadma L, Nguyen D, Parisey M, Wicky PH, Behillil S, Gaymard A, Bouscambert-Duchamp M, Donati F, Le Hingrat Q, Enouf V, Houhou-Fidouh N, Valette M, Mailles A, Lucet JC, Mentre F, Duval X, Descamps D, Malvy D, Timsit JF, Lina B, van-der-Werf S, Yazdanpanah Y, (2020) Clinical and virological data of the first cases of COVID-19 in Europe: a case series. Lancet Infect Dis. https://doi.org/10.1016/S1473 $-3099(20) 30200-0$ 
6. Chan MV, Armstrong PC, Papalia F, Kirkby NS, Warner TD (2011) Optical multichannel (optimul) platelet aggregometry in 96-well plates as an additional method of platelet reactivity testing. Platelets 22(7):485-494. https://doi.org/10.3109/09537 104.2011.592958

7. Temperilli F, Rina A, Massimi I, Montemari AL, Guarino ML, Zicari A, Pulcinelli FM (2015) Arachidonic acid-stimulated platelet tests: identification of patients less sensitive to aspirin treatment. Platelets 26(8):783-787. https://doi.org/10.3109/09537 104.2014.1003291

8. Temperilli F, Di Franco M, Massimi I, Guarino ML, Guzzo MP, Valesini G, Frati L, Pulcinelli FM (2016) Nonsteroidal antiinflammatory drugs in-vitro and in-vivo treatment and Multidrug Resistance Protein 4 expression in human platelets. Vascul Pharmacol 76:11-17. https://doi.org/10.1016/j.vph.2015.06.016

9. Riswari SF, Tunjungputri RN, Kullaya V, Garishah FM, Utari GSR, Farhanah N, Overheul GJ, Alisjahbana B, Gasem MH, Urbanus RT, de Groot PG, Lefeber DJ, van Rij RP, van der Ven A, de Mast Q (2019) Desialylation of platelets induced by Von Willebrand Factor is a novel mechanism of platelet clearance in dengue. PLoS Pathog 15(3):e1007500. https://doi.org/10.1371/ journal.ppat.1007500
10. Ranasinghe K, Dissanayaka D, Thirumavalavan K, Seneviratne M (2020) An unusual case of dengue shock syndrome complicated by ilio-femoral deep vein thrombosis; a case report. BMC Infect Dis 20(1):335. https://doi.org/10.1186/s12879-020-05062-y

11. Zander CB, Cao W, Zheng XL (2015) ADAMTS13 and von Willebrand factor interactions. Curr Opin Hematol 22(5):452-459. https://doi.org/10.1097/MOH.0000000000000169

12. Horby P, Lim WS, Emberson JR, Mafham M, Bell JL, Linsell L, Staplin N, Brightling C, Ustianowski A, Elmahi E, Prudon B, Green C, Felton T, Chadwick D, Rege K, Fegan C, Chappell LC, Faust SN, Jaki T, Jeffery K, Montgomery A, Rowan K, Juszczak E, Baillie JK, Haynes R, Landray MJ (2020) Dexamethasone in hospitalized patients with Covid-19 - preliminary report. New England J Med. https://doi.org/10.1056/NEJMoa2021436

Publisher's Note Springer Nature remains neutral with regard to jurisdictional claims in published maps and institutional affiliations.

\section{Affiliations}

Franco Ruberto ${ }^{1}$. Antonio Chistolini ${ }^{2} \cdot$ Mariaignazia Curreli $^{3}$. Giacomo Frati ${ }^{4,5}$ - Antonino G. M. Marullo ${ }^{4}$. Giuseppe Biondi-Zoccai ${ }^{4,6}$. Massimo Mancone ${ }^{7}$. Sebastiano Sciarretta ${ }^{4,5}$. Fabio Miraldi ${ }^{7}$. Francesco Alessandri ${ }^{1}$. Giancarlo Ceccarelli $^{8}$. Francesco Barone ${ }^{2}$. Cristina Santoro ${ }^{2}$. Domenico Alvaro ${ }^{9}$. Francesco Pugliese ${ }^{1}$. Fabio M. Pulcinelli ${ }^{3}$ - on behalf of Policlinico Umberto I COVID-19 Group

1 Department of General Surgery, Surgical Specialities and Organ Transplantation "Paride Stefanini" Sapienza University of Rome, Rome, Italy

2 Hematology, Department of Translational and Precision Medicine, Sapienza University of Rome, Rome, Italy

3 Department of Experimental Medicine, Sapienza University of Rome, Rome, Italy

4 Department of Medical-Surgical Sciences and Biotechnologies, Sapienza University of Rome, Latina, Italy

5 IRCCS NEUROMED, Pozzilli, Italy
6 Mediterranea Cardiocentro, Napoli, Italy

7 Department of Clinical, Internal Medicine, Anesthesiology and Cardiovascular Sciences, Sapienza University of Rome, Rome, Italy

8 Department of Public Health and Infectious Diseases, Sapienza University of Rome, Rome, Italy

9 Department of Translational and Precision Medicine, Sapienza University of Rome, Rome, Italy 